\title{
Consequences of prairie fragmentation on the progeny sex ratio of a gynodioecious species, Lobelia spicata (Campanulaceae)
}

\author{
DL Byers ${ }^{1}$, A Warsaw ${ }^{1}$ and TR Meagher ${ }^{2}$ \\ ${ }^{1}$ Department of Biological Sciences, Illinois State University, Campus Box 4120, Normal, IL 61790-4120, USA; ${ }^{2}$ Sir Harold Mitchell \\ Building, School of Biology, University of St Andrews, St Andrews, Fife KY16 9TH, UK
}

\begin{abstract}
Habitat fragmentation of prairie ecosystems has resulted in increased isolation and decreased size of plant populations. In large populations, frequency-dependent selection is expected to maintain genetic diversity of sex determining factors associated with gynodioecy, that is, nuclear restorer genes that reverse cytoplasmic male sterility (nucleocytoplasmic gynodioecy). However, genetic drift will have a greater influence on small isolated populations that result from habitat fragmentation. The genetic model for nucleocytoplasmic gynodioecy implies that the proportion of female progeny produced by hermaphroditic and female plants will show more extreme differences in populations with reduced allelic diversity, and that restoration of male function will increase with inbreeding. We investigated potential impacts of effects resulting from reduced population sizes by comparison of progeny sex ratios produced by female and hermaphroditic plants in small and large populations of the
\end{abstract}

gynodioecious prairie species, Lobelia spicata. A four-way contingency analysis of the impact of population size, population sex ratio, and maternal gender on progeny sex ratios showed that progeny sex ratios of hermaphroditic plants were strongly influenced by population size, whereas progeny sex ratios of female plants were strongly influenced by population sex ratio. Further, analysis of variation in progeny-type distribution indicated decreased restoration and increased loss of male function in smaller and isolated populations. These results are consistent with reduced allelic diversity or low allelic frequency at restorer loci in small and isolated populations. The consequent decrease in male function has the potential to impede seed production in these fragmented prairies.

Heredity (2005) 95, 69-75. doi:10.1038/sj.hdy.6800692

Published online 4 May 2005

Keywords: genetic drift; gynodioecy; habitat fragmentation; nucleocytoplasmic male sterility; prairies; sex ratio

\section{Introduction}

Many natural ecosystems are subject to habitat fragmentation, which results in smaller and more isolated populations. For instance, in the Midwest region of the United States the landscape was once dominated by prairies and savannas, but now such natural areas are isolated patches due to conversion of land for agriculture. Prairies and savannas are among the most endangered ecosystems (Klopatek et al, 1979; Noss et al, 1994). Plant species remaining in fragmented prairie habitats are of conservation concern due to impacts of decreased population size and increased isolation that threaten their viability due to genetic drift and consequent lower genetic diversity (Wright, 1969; Ellstrand and Elam, 1993).

Genetic diversity at breeding system loci is of particular relevance because of its impact on reproduction. For example, low genetic diversity at self-incompatibility loci reduces availability of compatible mates, resulting in reduced seed set (Byers and Meagher, 1992). Similarly, sex ratio dynamics of gynodioecious

Correspondence: DL Byers, Department of Biological Sciences, Illinois State University, Campus Box 4120, Normal, IL 61790-4120, USA.

E-mail: dlbyer2@ilstu.edu

Received 22 November 2004; accepted 18 March 2005; published online 4 May 2005 populations are typically determined by an interplay between cytoplasmic male sterility (cms) effects and genetic diversity at nuclear male fertility restorer loci (van Damme, 1986; Belhassen et al, 1993; Saumitou-Laprade et al, 1994; McCauley and Taylor, 1997; Charlesworth and Laporte, 1998; Dudle et al, 2001; Laporte et al, 2001). In the case of gynodioecy, genetic drift in small populations may result in loss of genetic diversity at restorer loci, which in turn would lead to a reduction in male function within populations, ultimately reducing seed set.

As mutations leading to new $\mathrm{cms}$ factors or restorer genes are infrequent, variation in such factors is most likely maintained in natural populations by migration among populations in a metapopulation landscape or by negative frequency-dependent selection within large populations (Frank, 1989; McCauley and Taylor, 1997; Laporte et al, 2001; Städler and Delph, 2002). However, populations in the highly fragmented prairie landscape of the Midwestern United States will be limited with regard to both migration and population size. Thus, we would expect genetic drift to lead to reduced diversity or frequency of nuclear restorers for male function, in turn resulting in an increased frequency of female progeny, limited availability of pollen, and ultimately reduced seed set (McCauley and Brock, 1998).

This study explores the impacts of population structure on breeding system variation in the gynodioecious 
species Lobelia spicata occurring in prairie fragments in the Midwestern United States. Specifically, we ask whether population size or population sex ratio has a detectable impact on progeny sex ratios and gender segregation patterns. A modeling exercise to explore the population behavior of nucleo-cms is followed by an empirical investigation of progeny arrays sampled from natural populations. We hypothesize that smaller populations should be subject to genetic drift at nuclear restorer loci, resulting in an increase in female progeny; whereas a high frequency of females in current populations, reflecting a loss of variation at male restorer loci that may in turn be a consequence of past genetic drift, will contribute to loss of male function among progeny.

Here, we have focused on genetic drift of the nuclear restorer genes, as it has the potential to impact directly the viability of the population through decreased seed set from limited male function in the population. Genetic drift could also impact the cytoplasmic genome, which could decrease female frequency and alter the mating system in a population that may or may not have important consequences for population viability.

\section{Study species and its habitat}

L. spicata Lam. (Campanulaceae) is a short-lived perennial species native to the tallgrass prairie region (Cochrane and Iltis, 2000). This species has a gynodioecious breeding system and is self-compatible (MolanoFlores, 2002). The gynodioecious breeding system of this species is most likely attributable to a balance between cms factors and nuclear genes that restore male function (nucleocytoplasmic control), as this has been shown to be the case in the closely related species L. siphilitica (Dudle et al, 2001). The proportion of female plants to hermaphrodites in prairies in Illinois ranges from 0.02 to 0.85 (DL Byers, unpublished data). Flowers of this species are visited by several small bees, small flies, and small butterflies, with Augochlorella striata (a small bee) being the primary visitor in Illinois (Molano-Flores, 2002; DL Byers, personal observation). The flowers are arranged in a terminal raceme with $2-70+$ flowers, and are sexually dimorphic for size (corolla flare), where the females $(8.4 \pm 0.098 \mathrm{~mm})$ are slightly, but significantly, smaller than the hermaphroditic flowers $(9.3 \pm 0.069 \mathrm{~mm}$; $\left.F_{1,769}=41.96, P<0.0001\right)$. This variation in corolla flare is heritable $\left(H^{2}=0.16-0.48\right)$ in the populations used in this study. Female flowers do not produce nectar, unlike hermaphroditic flowers, and thus have no reward for potential visitors in this species (Molano-Flores, 2002). It is not known if flower dimorphism influences insect visitation.

In Illinois, this species occurs in several different types of prairie including loess hill prairies, sandy savannas, and moist blacksoil tallgrass prairies (DL Byers, personal observation), which were once widespread throughout the Midwest region of the United States providing continuous habitat for L. spicata. Today, due to extensive agriculture, these suitable habitats are isolated (many km between fragments), surrounded by extensive corn and soybean fields, which are not suitable for L. spicata or its pollinators. At present, less than $1 \%$ of the prairie habitats remain in Illinois (Robertson et al, 1997). Thus, remaining $L$. spicata populations are very isolated, except for prairie preserves of a large size, where multiple populations are often present. Smaller fragments tend to sustain smaller populations, which are more likely to experience genetic drift.

\section{Materials and methods}

\section{Genetic model of sex determination}

In order to provide a conceptual framework for interpreting the empirical result, we present a genetic model of nucleocytoplasmic control of gynodioecy and a few predictions resulting from that model. Consider a population that is polymorphic for $\mathrm{cms}$ ( $\mathrm{cms} v s$ noncms) as well as for a locus that contains a dominant allele (R) that restores male function in the presence of $\mathrm{cms}$. Under this model, there is a range of genotypes that are hermaphroditic ( $(R R, c m s$ or noncms), ( $R r, c m s$ or noncms), (rr, noncms)) and one nuclear genotypecytoplasmic combination that is male-sterile ( $\mathrm{rr}, \mathrm{cms})$. To account for inbreeding, we include in this model a standard measure of inbreeding, $f$.

Under this model, genotype frequencies can be determined using standard calculations based on departures from Hardy-Weinberg equilibrium under inbreeding $\left(\mathrm{RR}=\left[p^{2}+f p q\right] ; \operatorname{Rr}=[2 p q(1-f)] ; \mathrm{rr}=\left[q^{2}+f p q\right]\right)$, and the population frequency of females (male-steriles) can be calculated by including the probability of having a male-sterile cytoplasm $\left(P_{\mathrm{cms}}\left[q^{2}+f p q\right]\right)$. From these frequencies, the probabilities of different mating combinations, and resultant progeny sex ratios, can be calculated for varying values of $p, P_{\mathrm{cms}}$, and $f$ (Table 1 ). This model inherently assumes random mating, which would not be the case in a gynodioecious population where the female plants could mate only with hermaphrodites, but simulation analyses (not presented) showed that genotype frequencies calculated as above differ from those obtained in simulated populations by no more than $0.04 \%$. Thus, this model represents a reasonable approximation of the dynamics of a gynodioecious population.

In order to explore a range of possibilities, we consider two extremes of both $\mathrm{cms}\left(P_{\mathrm{cms}}=1.0,0.5\right)$ and inbreeding $(f=0.0,0.5)$ over several frequencies for allele $\mathrm{R}$ (Figure 1). Considering first the frequency of females, among progeny, as the frequency of $\mathrm{R}$ increases the frequency of female progeny decreases for both hermaphroditic maternal plants and female maternal plants. When the frequency of male-sterile cytoplasm is lowered, the frequency of female progeny from hermaphroditic maternal parents goes down, but the occurrence of females in progeny from female maternal parents goes up dramatically. The reason for this is that the paternal genotype ( $r$, noncms) is nonexistent when $\mathrm{cms}$ is fixed $\left(P_{\mathrm{cms}}=1.0\right)$, but does occur when $P_{\text {cms }}<1$, making it possible for the rr genotype to serve as a paternal parent. Adding inbreeding has little effect on these relationships.

The other outcome we will be considering in the empirical study is the distribution of segregating progeny types from different maternal parents (eg all female, all hermaphroditic, or mixed). Under the model for fixed cms and no inbreeding, there are no progeny arrays expected that are all female, and a high proportion of mixed sibships at low frequencies of $\mathrm{R}$ reverses at high frequencies of R (Figure 2, panel a). When $P_{\mathrm{cms}}<1.0$, this relationship changes dramatically, with hermaphrodites 
Table 1 Population genetic basis for estimation of progeny gender proportions and progeny structure under varying probability of carrying a male-sterile cytoplasm $\left(P_{\mathrm{cms}}\right)$, frequency $(p)$ of a dominant restorer allele $(\mathrm{R})$, and inbreeding $(f)$.

\begin{tabular}{|c|c|c|c|c|c|c|c|}
\hline \multirow[t]{3}{*}{ Cytotypes } & \multirow[t]{3}{*}{ Maternal genotype } & \multirow[t]{3}{*}{ Paternal genotype } & \multirow[t]{3}{*}{ Cross probability } & \multicolumn{4}{|c|}{ Progeny segregation } \\
\hline & & & & \multicolumn{3}{|c|}{ Hermaphroditic } & \multirow{2}{*}{$\begin{array}{l}\text { Female } \\
\operatorname{rr}(\mathrm{cms})\end{array}$} \\
\hline & & & & $R R$ & $R r$ & $\operatorname{rr}($ non) & \\
\hline \multicolumn{8}{|c|}{ Hermaphroditic maternal parents } \\
\hline Both $\times$ both $^{\text {a }}$ & RR & $\mathrm{RR}$ & $\left(p^{2}+f p q\right)^{2}$ & 1 & 0 & 0 & 0 \\
\hline Both $\times$ both & RR & $\mathrm{Rr}$ & $\left(p^{2}+f p q\right)(2 p q(1-f))$ & 0.5 & 0.5 & 0 & 0 \\
\hline $\mathrm{Cms} \times$ noncms & RR & $\mathrm{rr}$ & $P_{\mathrm{cms}}\left(1-P_{\mathrm{cms}}\right)\left(p^{2}+f p q\right)\left(q^{2}+f p q\right)$ & 0 & 1 & 0 & 0 \\
\hline $\mathrm{Cms} \times \mathrm{cms}$ & $\mathrm{RR}$ & $\mathrm{rr}$ & $\operatorname{Null}^{\mathrm{b}}\left[P_{\mathrm{cms}}^{2}\left(p^{2}+f p q\right)\left(q^{2}+f p q\right)\right]$ & 0 & 0 & 0 & 0 \\
\hline Noncms $\times$ noncms & RR & $\mathrm{rr}$ & $\left(1-P_{\mathrm{cms}}\right)^{2}\left(p^{2}+f p q\right)\left(q^{2}+f p q\right)$ & 0 & 1 & 0 & 0 \\
\hline Noncms $\times \mathrm{cms}$ & RR & $\mathrm{rr}$ & Null $\left[\left(1-P_{c \mathrm{cms}}\right) P_{\mathrm{cms}}\left(p^{2}+f p q\right)\left(q^{2}+f p q\right)\right]$ & 0 & 0 & 0 & 0 \\
\hline Both $\times$ both & $\mathrm{Rr}$ & RR & $(2 p q(1-f)) p^{2}$ & 0.5 & 0.5 & 0 & 0 \\
\hline $\mathrm{Cms} \times$ both & $\operatorname{Rr}$ & $\mathrm{Rr}$ & $P_{\mathrm{cms}}(2 p q(1-f))^{2}$ & 0.25 & 0.5 & 0 & 0.25 \\
\hline Noncms $\times$ both & $\mathrm{Rr}$ & $\mathrm{Rr}$ & $\left(1-P_{\mathrm{cms}}\right)(2 p q(1-f))^{2}$ & 0.25 & 0.5 & 0.25 & 0 \\
\hline $\mathrm{Cms} \times$ noncms & $\mathrm{Rr}$ & $\mathrm{rr}$ & $P_{\mathrm{cms}}\left(1-P_{\mathrm{cms}}\right)(2 p q(1-f)) q^{2}$ & 0 & 0.5 & 0 & 0.5 \\
\hline $\mathrm{Cms} \times \mathrm{cms}$ & $\mathrm{Rr}$ & $\mathrm{rr}$ & Null $\left[P_{\mathrm{cms}}^{2}(2 p q(1-f)) q^{2}\right]$ & 0 & 0 & 0 & 0 \\
\hline Noncms $\times$ noncms & $\operatorname{Rr}$ & $\mathrm{rr}$ & $\left(1-P_{\mathrm{cms}}\right)^{2}(2 p q(1-f)) q^{2}$ & 0 & 0.5 & 0.5 & 0 \\
\hline Noncms $\times \mathrm{cms}$ & $\operatorname{Rr}$ & $\mathrm{rr}$ & Null $\left[\left(1-P_{\mathrm{cms}}\right) P_{\mathrm{cms}}(2 p q(1-f)) q^{2}\right]$ & 0 & 0 & 0 & 0 \\
\hline Noncms $\times$ both & $\mathrm{rr}$ & RR & $\left(1-P_{\mathrm{cms}}\right)\left(q^{2}+f p q\right)\left(p^{2}+f p q\right)$ & 0 & 1 & & 0 \\
\hline Noncms $\times$ both & $\mathrm{rr}$ & $\operatorname{Rr}$ & $\left(1-P_{\mathrm{cms}}\right)\left(q^{2}+f p q\right)(2 p q(1-f))$ & 0 & 0.5 & 0.5 & 0 \\
\hline Noncms $\times$ noncms & $\mathrm{rr}$ & $\mathrm{rr}$ & $\left(1-P_{\mathrm{cms}}\right)\left(1-P_{\mathrm{cms}}\right)\left(q^{2}+f p q\right)^{2}$ & 0 & 0 & 1 & 0 \\
\hline Noncms $\times \mathrm{cms}$ & rr & $\mathrm{rr}$ & Null $\left[\left(1-P_{\mathrm{cms}}\right) P_{\mathrm{cms}}\left(q^{2}+f p q\right)^{2}\right]$ & 0 & 0 & 0 & 0 \\
\hline \multicolumn{8}{|c|}{ Female (male-sterile) maternal parents } \\
\hline Cms $\times$ both & $\mathrm{rr}$ & RR & $P_{\mathrm{cms}}\left(q^{2}+f p q\right)\left(p^{2}+f p q\right)$ & 0 & 1 & 0 & 0 \\
\hline Cms $\times$ both & $\mathrm{rr}$ & $\mathrm{Rr}$ & $P_{\mathrm{cms}}\left(q^{2}+f p q\right)(2 p q(1-f))$ & 0 & 0.5 & 0 & 0.5 \\
\hline $\mathrm{Cms} \times$ noncms & $\mathrm{rr}$ & $\mathrm{rr}$ & $P_{\mathrm{cms}}\left(1-P_{\mathrm{cms}}\right)\left(q^{2}+f p q\right)^{2}$ & 0 & 0 & 0 & 1 \\
\hline $\mathrm{Cms} \times \mathrm{cms}$ & $\mathrm{rr}$ & $\mathrm{rr}$ & Null $\left[P_{\mathrm{cms}}^{2}\left(q^{2}+f p q\right)^{2}\right]$ & 0 & 0 & 0 & 0 \\
\hline
\end{tabular}

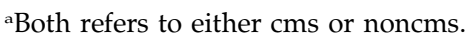

${ }^{b}$ Null refers to combinations that will result in no progeny.
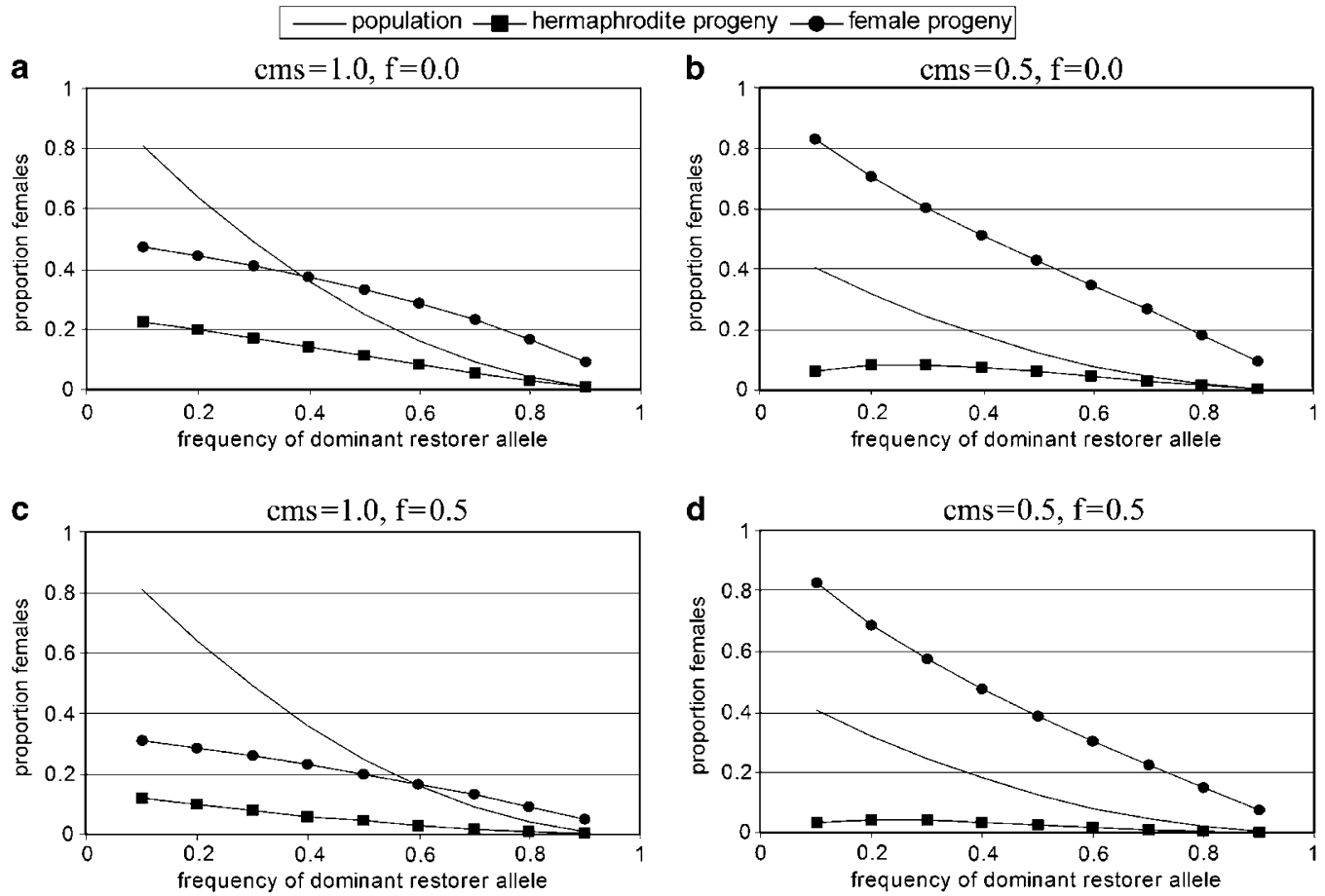

Figure 1 Expected proportion of female progeny from hermaphroditic maternal parents and female maternal parents compared to expected population-level proportion of females. The different panels illustrate the effects of varying frequencies of occurrence of cytoplasmic male sterility (cms), inbreeding $(f)$, and frequency of nuclear male restorer alleles on these sex ratios. Panels ' $a$ ' and ' $b$ ' consider the dynamics with high or low level of cms, respectively, where there is no inbreeding (as with a very large population). Panels ' $\mathrm{c}$ ' and ' $\mathrm{d}$ ' show the population dynamics considering these two levels of $\mathrm{cms}$, but with an inbreeding coefficient of 0.5 as may be expected in a smaller population. 


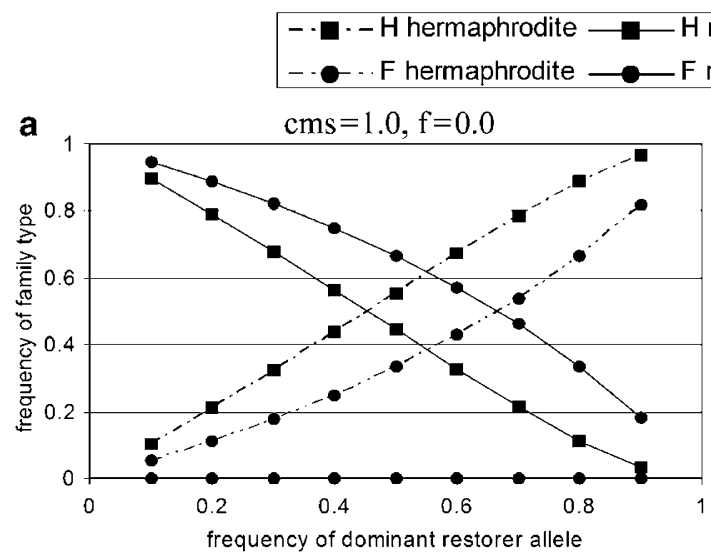

$\begin{array}{lll}H \text { mixed } & \cdots \cdot \cdots & F \text { female } \\ F \text { mixed } & \end{array}$

c

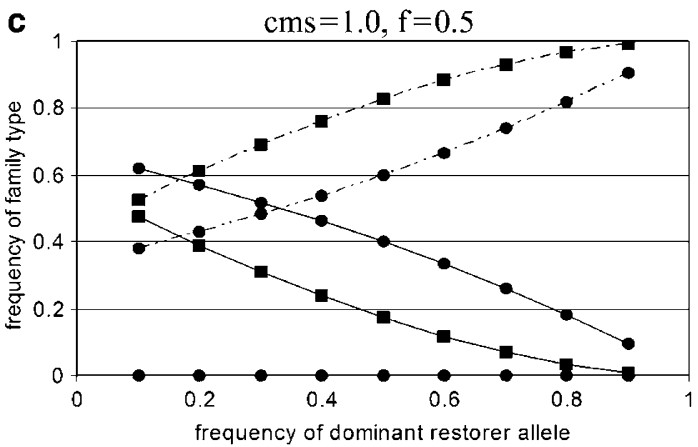

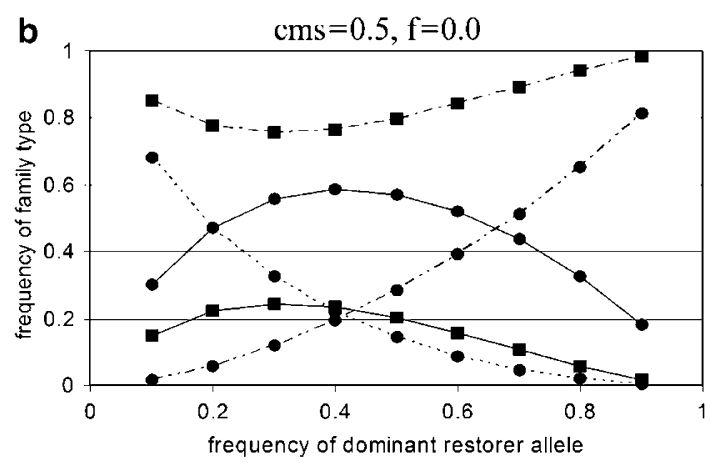

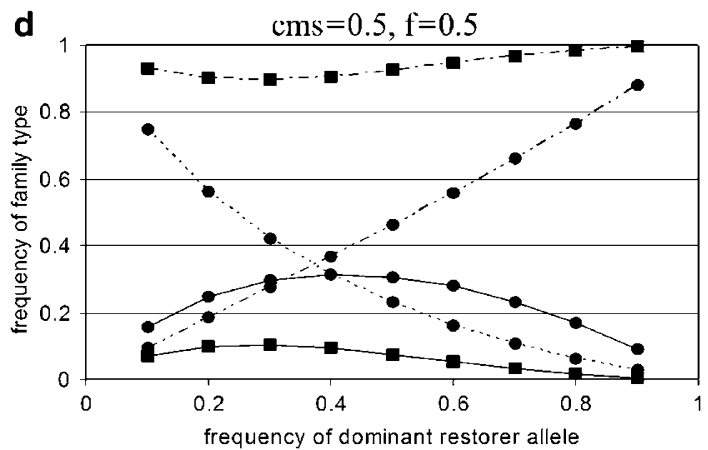

Figure 2 Expected proportion of progeny arrays segregating as all female, all hermaphroditic, or mixed gender from hermaphroditic maternal parents or female maternal parents. The different panels illustrate the effects of varying frequencies of occurrence of cytoplasmic male sterility (cms), inbreeding ( $f$ ), and frequency of nuclear male restorer alleles on the offspring expected proportions. Panels ' $a$ ' and ' $b$ ' consider the dynamics with high or low level of $\mathrm{cms}$, respectively, where there is no inbreeding (as with a very large population). Panels ' $\mathrm{c}$ ' and ' $\mathrm{d}$ ' show the population dynamics considering these two levels of cms, but with an inbreeding coefficient of 0.5 as may be expected in a smaller population.

producing a high frequency of all hermaphroditic progeny arrays at all frequencies of $R$, females producing a high frequency of all female progeny arrays when the frequency of $R$ is low, and the proportion of mixed progeny arrays for both types of maternal plants being higher for intermediate frequencies of $\mathrm{R}$ (Figure 2, panel b). Inbreeding has a fairly strong impact on segregation patterns, generally increasing the probability of all hermaphroditic progenies and decreasing the probability of mixed progenies (Figure 2, panels $\mathrm{c}$ and d).

\section{Study populations}

This study focuses on four prairies in central Illinois, of which two (Hooper Branch Savanna and Revis Hill Prairie) are larger sized fragments ( $>162$ hectares) in which there are a number of $L$. spicata populations with some being numerous (>1000 flowering plants; designated $L$ in Tables 2a and 3a). The other two prairies (Weston Cemetery Prairie and Witter's Bobtown Hill Prairie) are smaller fragments $(<4.5 \mathrm{ha})$ in which there are only one to two local L. spicata populations that are small in size $(\sim 300$ flowering plants, designated $S$ in Tables 2a and 3a). Two of the populations in this study had a high percentage of females (Hooper Branch Savanna 40\% and Weston Cemetery Prairie 55\%; designated $\mathrm{F}$ in Tables $2 \mathrm{a}$ and $3 \mathrm{a}$ ), while the other two were made up mostly of hermaphrodites (Revis Hill Prairie 8\% female and Witter's Bobtown Hill Prairie 7\% female; designated $\mathrm{H}$ in Tables $2 \mathrm{a}$ and $3 \mathrm{a}$ ). The populations are located on old prairie remnants.

In all, 50 maternal plants in each population were randomly sampled across the entire local population for fruits. In the hermaphroditic-biased populations, we randomly chose plants until at least 10 females were in our sample. Our goal was to sex progeny of 50 plants from each population by growing nine progeny per plant (three individuals from each of three fruits). However, due to biological limitations, we sampled somewhat fewer plants per population (36-48), and some plants had fewer progeny. All of the progeny were grown in the greenhouse to flowering, and then sexed.

\section{Data analysis}

To assess if population sex ratio, population size, or maternal gender impacts the progeny sex ratio, the number of female and hermaphroditic progeny produced was evaluated using a hierarchical four-way contingency analysis (Bishop et al, 1975; Sokal and Rohlf, 1995). We used an iterative approach, which tests the fit of the most complex model to the data starting with the highest order interaction term. If the highest order interaction term is not significant, the next level of interactions can be considered. If an interaction term is significant, then the various interactions and factors nested within that interaction are considered separately. In terms of our initial questions, the two-way 
Table 2 Sex ratio of the progeny and results from hierarchical contingency analysis of population size, population sex ratio, and maternal gender impact on progeny sex ratio. (a) Summarized data and (b) hierarchical contingency analysis

\begin{tabular}{|c|c|c|c|c|c|c|}
\hline \multirow[t]{2}{*}{ Parental population } & \multicolumn{3}{|c|}{ Maternal hermaphrodite } & \multicolumn{3}{|c|}{ Maternal female } \\
\hline & $\mathrm{N}$ & $\% \mathrm{~F}$ & $\% \mathrm{H}$ & $\mathrm{N}$ & $\% \mathrm{~F}$ & $\% \mathrm{H}$ \\
\hline \multicolumn{7}{|l|}{ (a) Summarized data } \\
\hline Weston (SF) & 86 & 19.8 & 80.2 & 76 & 61.8 & 38.2 \\
\hline Hooper branch (LF) & 147 & 4.8 & 95.2 & 138 & 62.3 & 37.7 \\
\hline Witter's (SH) & 266 & 26.7 & 73.3 & 72 & 40.3 & 59.7 \\
\hline Revis (LH) & 153 & 7.0 & 93.0 & 67 & 48.9 & 51.1 \\
\hline Model effect & $d f$ & $L L R$ & P-value & & & \\
\hline \multicolumn{7}{|l|}{ (b) Hierarchical contingency analysis } \\
\hline Pop size $\times$ pop sex ratio $\times$ maternal gender $\times$ progeny sex ratio & 1 & 0.26 & 0.6101 & & & \\
\hline Pop size $\times$ pop sex ratio $\times$ progeny sex ratio & 2 & 0.48 & 0.7866 & & & \\
\hline Pop size $\times$ maternal gender $\times$ progeny sex ratio & 2 & 24.90 & $<0.0001$ & & & \\
\hline Pop size $\times$ progeny sex ratio (female plants) & 2 & 0.87 & 0.6473 & & & \\
\hline Pop size $\times$ progeny sex ratio (hermaphroditic plants) & 2 & 41.66 & $<0.0001$ & & & \\
\hline Pop sex ratio $\times$ maternal gender $\times$ progeny sex ratio & 2 & 10.21 & 0.0061 & & & \\
\hline Pop sex ratio × progeny sex ratio (female plants) & 2 & 9.50 & 0.0087 & & & \\
\hline Pop sex ratio $\times$ progeny sex ratio (hermaphroditic plants) & 2 & 2.17 & 0.3379 & & & \\
\hline
\end{tabular}

$\mathrm{LLR}=\log$-likelihood ratio; $\mathrm{S}=$ small pop; $\mathrm{F}=$ female bias; $\mathrm{L}=$ large pop; $\mathrm{H}=$ hermaphrodite bias.

Table 3 Distribution of progeny types produced by maternal hermaphroditic and female plants. (a) Summarized data and (b) hierarchical contingency analysis

\begin{tabular}{|c|c|c|c|c|c|c|c|c|}
\hline \multirow[t]{2}{*}{ Parental population } & \multicolumn{4}{|c|}{ Maternal hermaphrodite } & \multicolumn{4}{|c|}{ Maternal female } \\
\hline & $\mathrm{N}$ & $\begin{array}{l}\% \text { All } \\
\text { female }\end{array}$ & $\begin{array}{c}\% \text { All } \\
\text { hermaphrodite }\end{array}$ & $\begin{array}{l}\% \text { Mixed } \\
\text { gender }\end{array}$ & $\mathrm{N}$ & $\begin{array}{l}\% \text { All } \\
\text { female }\end{array}$ & $\begin{array}{c}\% \text { All } \\
\text { hermaphrodite }\end{array}$ & $\begin{array}{l}\text { \% Mixed } \\
\text { gender }\end{array}$ \\
\hline \multicolumn{9}{|l|}{ (a) Summarized data } \\
\hline Weston (SF) & 18 & 0 & 50.0 & 50.0 & 19 & 57.9 & 10.5 & 31.6 \\
\hline Hooper branch (LF) & 25 & 0 & 88.0 & 12.0 & 24 & 8.3 & 0 & 91.7 \\
\hline Witter's (SH) & 37 & 0 & 27.0 & 73.0 & 9 & 0 & 0 & 100.0 \\
\hline Revis (LH) & 29 & 0 & 75.9 & 24.1 & 9 & 0 & 0 & 100.0 \\
\hline Model effect & $d f$ & $L L R$ & P-value & & & & & \\
\hline \multicolumn{9}{|l|}{ (b) Hierarchical contingency analysis } \\
\hline Pop size $\times$ pop sex ratio $\times$ maternal gender $\times$ progeny type & 2 & 0.00 & 1.0000 & & & & & \\
\hline Pop sex ratio $\times$ maternal gender $\times$ progeny type & 4 & 1.51 & 0.8249 & & & & & \\
\hline Pop size $\times$ maternal gender $\times$ progeny type & 4 & 10.73 & 0.0298 & & & & & \\
\hline Maternal gender $\times$ progeny type (S) & 2 & 31.12 & $<0.0000$ & & & & & \\
\hline Maternal gender $\times$ progeny type $(\mathrm{L})$ & 2 & 69.93 & $<0.0000$ & & & & & \\
\hline Pop size $\times$ progeny type $(\mathrm{H})$ & 1 & 25.79 & $<0.0000$ & & & & & \\
\hline Pop size $\times$ progeny type $(\mathrm{F})$ & 2 & 14.90 & 0.0006 & & & & & \\
\hline Pop size $\times$ pop sex ratio $\times$ progeny type & 4 & 0.02 & 1.0000 & & & & & \\
\hline Pop sex ratio $\times$ progeny type & 8 & 20.42 & 0.0089 & & & & & \\
\hline
\end{tabular}

$\mathrm{S}=$ small pop; $\mathrm{F}=$ female bias; $\mathrm{L}=$ large pop; $\mathrm{H}=$ hermaphrodite bias.

interactions of population size by progeny sex ratio and population sex ratio by progeny sex ratio are of particular interest.

In order to further evaluate gain or loss of male function, we examined the type of segregating progenies produced by each maternal plant, classifying progeny arrays as all female, all hermaphrodite (only hermaphrodites), or mixed (some of each). A maternal female's progeny consisting of mixed or all hermaphrodites would indicate a gain of male function, and a maternal hermaphrodite's progeny that is mixed or all female would represent a loss of male function. Again, we used a hierarchical four-way contingency analysis, along the same lines as above (population size $\times$ population sex ratio $\times$ maternal gender $\times$ progeny type). Gain or loss of male function is evaluated through the two-way interaction of maternal gender $\times$ progeny type.

\section{Results}

\section{Progeny sex ratio}

Results from the hierarchical contingency analysis indicated a significant interaction between population size, maternal gender, and progeny sex ratio; thus, the effect of population size on progeny sex ratio was run separately by maternal gender (Table $2 a$ and $b$ ). Similarly, the analysis found a significant interaction between population sex ratio, maternal gender, and progeny sex ratio; hence, this analysis was also carried out by 
maternal gender. The results from follow-up analyses indicated that population size significantly impacted the progeny sex ratio, but only for progeny from hermaphrodites. On the other hand, population sex ratio influences the progeny sex ratio, but only for progeny from females (Table $2 b$ ).

\section{Progeny segregation: gain or loss of male function}

In both of the larger populations, most of the families derived from hermaphroditic maternal plants were all hermaphrodites (Table 3a). In the smaller populations, regardless of the population sex ratio, families of mixed sex were common. These results suggest that there is a greater loss of male fertility in the smaller populations than in the larger populations.

Among the female maternal plants of the hermaphroditic-biased populations, there was no difference between the small and large populations; all produced mixed-sex families (Table 3b). However, in the analysis of the female-biased populations, families derived from female maternal plants of the smaller population (Weston) produced significantly more all-female families than the larger population (Hooper Branch). Therefore, the potential for genetic drift to impact the gain of male function (female plants producing hermaphrodites) depends on population sex ratio.

\section{Discussion}

Many natural areas are becoming increasingly fragmented resulting in smaller and more isolated populations of the remaining species. The consequences of such isolation are likely to be increased inbreeding, and in turn greater exposure to genetic drift, resulting in loss of genetic diversity.

The genetic model for nucleocytoplasmic control of gynodioecy provides a basis for making predictions about the relationship between gene frequencies and gender dynamics in equilibrium populations. This model demonstrated that the different maternal gender types show differences in the proportion of female progeny that varies with frequency of restorer alleles, with convergence as restorer alleles become more frequent. This model also demonstrates that restoration of male function should increase as the frequency of the restorer allele increases. Since the overall proportion of females in a population is inversely related to frequency of restorer alleles, this model mostly addresses the expected relationship between population sex ratio and progeny arrays. In terms of population size, model results mostly provide base-line expectations for large populations. However, if one extrapolates to multiple restorer loci, then the frequency of females expected in a population goes down substantially with each added locus. Thus, a relatively high frequency of females could result from a low frequency of the restorer allele at one locus, or from a loss of restorer alleles due to genetic drift across several loci.

Differences in the progeny sex ratios and the distribution of families in the smaller/isolated vs larger/ nonisolated populations support our hypothesis that genetic drift is impacting the breeding system loci. In particular, hermaphrodites in the smaller populations produced more female progeny compared to the hermaphrodites in the larger populations, reflecting lowered genetic diversity at restorer loci. Furthermore, the families produced by hermaphrodites in the smaller/ isolated populations (both population sex ratios) had a greater proportion of the mixed-sex families. Since these families are from hermaphroditic plants, this result indicates that the plants in the smaller/isolated populations have a greater loss of male function relative to the larger/unisolated populations.

The results of the progeny sex ratio and progeny distribution from female plants reveal a different pattern. The progeny sex ratio was influenced by the population sex ratio but not the size/isolation of the population. This result suggests that the progeny sex ratio of female plants is more influenced by the population sex ratio than genetic drift. However, the smaller female-biased population produced more exclusively female families than the larger female-biased population. Since these are female plants, an increased frequency of female progeny in the smaller populations suggests that genetic drift has impacted the nuclear restorers.

The underlying cause of the increased number of female progeny could be due to either a lack of some of the correct restorers for the cms alleles or that they occur at a low frequency. The fitness consequences and significance of this apparent limited restoration and gain of male function in these populations are not known.

While other studies to our knowledge have not examined the potential of genetic drift on the loci controlling expression of gynodioecy, the effect of population sex ratio has been examined in Silene vulgaris. The progeny sex ratios of $S$. vulgaris in the local populations of a metapopulation were determined by the parental sex ratio in the local population and were consistent across generations, which were interpreted as evidence for genetic basis for the sex ratio among populations (McCauley et al, 2000). While the fitness consequences due to genetic drift of the breeding system loci are not known, the genetic characteristics (diversity for sterility, correct diversity for restoration, and relative frequency of alleles) can impact the sex ratio and fitness of both sexes (McCauley and Brock, 1998; McCauley et al, 2000; Asikainen and Mutikainen, 2003). Female relative fitness (the number of seeds per capsule) increased in populations with few females (McCauley et al, 2000). However, in the gynodioecious species Geranuim sylvaticum, the relative fitness of hermaphrodites (seed production) increased in population with fewer females (Asikainen and Mutikainen, 2003). These studies illustrate that the impact of sex ratio on fitness may be species dependent. Thus, genetic drift of these loci may impact fitness of the populations through changes in sex ratio.

In small populations of species with a self-incompatible breeding system, the impact of genetic drift resulted in limited diversity or nonequilibrium allele frequencies, which often resulted in lower reproduction (Les et al, 1991; Byers and Meagher, 1992; DeMauro, 1993; Byers, 1995; Young et al, 2000). The joint effect of small population size and isolation on gynodioecious species needs to be further investigated to determine if genetic drift of these loci occurs and what the consequences for fitness are for gynodioecious species, as has been explored in self-incompatible species.

Another possible explanation for the different sex ratio in the smaller vs larger populations is increased selfing in the smaller populations. A recent study of $S$. vulgaris 
(nucleocytoplasmically determined gynodioecy) found increased frequency of female progeny from selfed hermaphrodites (Emery and McCauley, 2002). The nuclear restorer alleles act as a dominant allele; thus, selfing increases the frequency of homozygous recessive genotypes and the number of females (Emery and McCauley, 2002). Therefore, the pattern of frequency of female progeny from hermaphroditic plants in smaller/ isolated populations may also be due to increased selfing.

To our knowledge, this is the first study suggesting that genetic drift in small and isolated populations is influencing the extent of genetic diversity at the breeding system loci in a gynodioecious species. Given the results of this study, which uses a limited number of populations, further studies using more populations of this species and other species are needed to determine if this is a general pattern for gynodioecious species.

\section{Acknowledgements}

We thank Charles E Bristow and Carie Weddle for assistance in the prairie sites; CEB for assistance in the greenhouse; Matt S Olson, Lynda F Delph, and CEB for reading earlier versions of this paper; Don Schmidt for excellent care of the plants in the greenhouses; ISU for faculty grant support; and IL DNR and land owners for permission to conduct research on nature preserves.

\section{References}

Asikainen E, Mutikainen P (2003). Female frequency and relative fitness of females and hermaphrodites in gynodioecious Geranium sylvaticum (Geraniaceae). Am J Bot 90: 226-234.

Belhassen E, Atlan A, Couvet D, Gouyon P-H, Quétier F (1993). Mitochondrial genome of Thymus vulgaris L. (Labiatae) is highly polymorphic between and among natural populations. Heredity 71: 462-472.

Bishop YMM, Fienberg SE, Holland PW (1975). Discrete Multivariate Analysis: Theory and Practice. MIT Press: Cambridge, MA.

Byers DL (1995). Pollen quantity and quality as explanations for low seed set in small populations exemplified by Eupatorium (Asteraceae). Am J Bot 82: 1000-1006.

Byers DL, Meagher TR (1992). Mate availability in small populations of plant species with homomorphic sporophytic self-incompatibility. Heredity 68: 353-359.

Charlesworth D, Laporte V (1998). The male-sterility polymorphism of Silene vulgaris: Analysis of genetic data from two populations and comparison with Thymus vulgaris. Genetics 150: 1267-1282.

Cochrane TS, Iltis HH (2000). Atlas of the Wisconsin Prairie and Savanna Flora. Technical Bulletin No. 191. Bureau of Integrated Sciences Services Research Center, Department of Natural Resources: Monanona, WI.

DeMauro MM (1993). Relationship of breeding system to rarity in the lakeside daisy (Hymenoxys acaulis var. glabra). Conserv Biol 7: 542-550.
Dudle DA, Mutikainen P, Delph LF (2001). Genetics of sex determination in the gynodioecious species Lobelia siphilitica: evidence from two populations. Heredity 86: 265-276.

Ellstrand NC, Elam DR (1993). Population genetic consequences of small population size: implications for plant populations. Annu Rev Ecol Syst 24: 217-242.

Emery SN, McCauley DE (2002). Consequences of inbreeding for offspring fitness and gender in Silene vulgaris, a gynodioecious plant. J Evol Biol 15: 1057-1066.

Frank SA (1989). The evolutionary dynamics of cytoplasmic male sterility. Am Nat 133: 345-376.

Klopatek JR, Olson RJ, Emerson CJ, Joness JL (1979). Land-use conflicts with natural vegetation in the United States. Environ Conserv 6: 191-199.

Laporte V, Viard F, Bena G, Valero M, Cuguen J (2001). The spatial structure of sexual and cytonuclear polymorphism in the gynodioecious Beta vulgaris ssp. Maritma: I at a local scale. Genetics 157: 1699-1710.

Les DH, Reinartz JA, Esselman EJ (1991). Genetic consequences of rarity in Aster furcatus (Asteraceae), a threatened, selfincompatible plant. Evolution 45: 1641-1650.

McCauley DE, Brock MT (1998). Frequency-dependent fitness in Silene vulgaris, a gynodioecious plant. Evolution 52: 30-36.

McCauley DE, Olson MS, Emery SN, Taylor DR (2000). Population structure influences sex ratio evolution in a gynodioecious plant. Am Nat 155: 814-819.

McCauley DE, Taylor DR (1997). Local population structure and sex ratio: evolution in gynodioecious plants. Am Nat 150: 406-419.

Molano-Flores B (2002). Pollination biology and flower visitors of the gynodioecious species Lobelia spicata Lam. (Campanulaceae). J Torrey Bot Soc 129: 187-193.

Noss RF, LaRoa III ET, Scott JM (1994). Endangered Ecosystems of the United States: A Preliminary Assessment of Loss and Degradation. US Department of Interior National Biological Service, Biological Report No. 28: Washington, DC.

Robertson KR, Anderson RC, Schwartz MW (1997). The tallgrass prairie mosaic. In: Schwartz MW (ed) Conservation in Highly Fragmented Landscapes. Chapman \& Hall: New York. pp 55-87.

Saumitou-Laprade P, Cuguen J, Vernet P (1994). Cytoplasmic male sterility in plants: molecular evidence and the nucleocytoplasmic conflict. Trends Ecol Evol 9: 431-435.

Sokal RR, Rohlf FJ (1995). Biometry, 2nd edn, WH Freeman and Co.: New York.

Städler T, Delph LF (2002). Ancient mitochondrial haplotypes and evidence for intragenic recombination in a gynodioecious plant. Proc Natl Acad Sci USA 99: 11730-11735.

van Damme JMM (1986). Gynodioecy in Plantago lanceolata L.V. Frequencies and spatial distribution of nuclear and cytoplasmic genes. Heredity 56: 355-364.

Wright S (1969). Evolution and the Genetics Of Populations, Vol 2. University of Chicago Press: Chicago.

Young AG, Brown AHD, Murray BG, Thrall PH, Miller C (2000). Genetic erosion, restricted mating and reduced viability in fragmented populations of the endangered grassland herb Rutidosis leptorrhynchoides. In: Young AG, Clarke GM (eds) Genetic, Demography and Viability of Fragmentation Populations. Cambridge University Press: Cambridge, MA. pp 335-360. 